Philip C. Calder

Gordon L. Jensen

Berthold V. Koletzko

Pierre Singer

Geert J. A. Wanten

\section{Lipid emulsions in parenteral nutrition of intensive care patients: current thinking and future directions}

Received: 3 August 2009

Accepted: 28 December 2009

Published online: 14 January 2010

(C) The Author(s) 2010. This article is published with open access at

Springerlink.com

\section{P. C. Calder}

Institute of Human Nutrition,

University of Southampton,

Southampton, UK

\section{G. L. Jensen}

Department of Nutritional Sciences,

The Pennsylvania State University,

University Park, PA, USA

\section{B. V. Koletzko}

Division of Metabolic Disease and Nutritional Medicine, Dr. von Hauner Children's Hospital, University of Munich

Medical Centre, Munich, Germany

\section{P. Singer}

Department of General Intensive Care, Rabin Medical Center, Sackler School of Medicine, Tel Aviv University, Tel Aviv, Israel

G. J. A. Wanten

Department of Gastroenterology and Hepatology, Radboud University Nijmegen Medical Centre, Nijmegen, The Netherlands
P. C. Calder ( $\bullet$ )

School of Medicine, University of Southampton, IDS Building, MP887 Southampton General Hospital, Tremona Road,

Southampton SO16 6YD, UK

e-mail: pcc@soton.ac.uk

Tel.: +44-2380-795250

Fax: +44-2380-795255

\begin{abstract}
Background: Energy deficit is a common and serious problem in intensive care units and is associated with increased rates of complications, length of stay, and mortality. Parenteral nutrition (PN), either alone or in combination with enteral nutrition, can improve nutrient delivery to critically ill patients. Lipids provide a key source of calories within PN formulations, preventing or correcting energy deficits and improving outcomes. Discussion: In this article, we review the role of parenteral lipid emulsions (LEs) in the management of critically ill patients and highlight important biologic activities associated with lipids. Soybean-oil-based LEs with high contents of polyunsaturated fatty acids (PUFA) were the first widely used formulations in the intensive
\end{abstract}

care setting. However, they may be associated with increased rates of infection and lipid peroxidation, which can exacerbate oxidative stress. More recently developed parenteral LEs employ partial substitution of soybean oil with oils providing medium-chain triglycerides, $\omega-9$ monounsaturated fatty acids or $\omega-3$ PUFA. Many of these LEs have demonstrated reduced effects on oxidative stress, immune responses, and inflammation. However, the effects of these LEs on clinical outcomes have not been extensively evaluated. Conclusions: Ongoing research using adequately designed and well-controlled studies that characterize the biologic properties of LEs should assist clinicians in selecting LEs within the critical care setting. Prescription of PN containing LEs should be based on available clinical data, while considering the individual patient's physiologic profile and therapeutic requirements.

Keywords Energy deficit . Fatty acid - Intensive care . Lipid emulsion - Parenteral nutrition

\section{Introduction}

Many critically ill patients admitted to the intensive care unit (ICU) enter a state of negative energy balance during the first 3-4 days following admission $[1,2]$. This energy deficit often progresses during their ICU stay and may result in malnutrition and adverse outcomes [1]. Multiple factors contribute to energy deficit, including increased 
metabolism [3, 4], delays in the initiation of feeding, and inadequate caloric provision [1]. Indeed, a number of studies have demonstrated that target caloric intake is achieved in only $50-75 \%$ of ICU patients and that as many as $25 \%$ of patients receive only $1,000-1,500 \mathrm{kcal} /$ day [5].

Prolonged negative energy balance within the ICU is associated with serious complications $[1,2]$. In two separate studies, progressive negative energy balance was strongly correlated with increased numbers of infectious complications, particularly sepsis [1, 2]. In addition, cumulative total energy deficit has been correlated with increased length of mechanical ventilation, length of ICU stay, total number of complications, and duration of antibiotic use [1]. Delayed initiation of feeding and/or negative energy balance in critical care patients may also be associated with higher ICU and in-hospital mortality rates $[5,6]$, while early initiation of feeding results in improved caloric intake [7].

This article aims to review well-known papers that evaluate potential biologic effects of lipids when provided as a parenteral energy source and to provide future perspectives on the use of parenteral lipid emulsions (LEs) in critically ill patients.

\section{Role of parenteral nutrition in the intensive care setting}

Given the association between negative energy balance/ malnutrition and both morbidity and mortality, ensuring that critically ill patients receive adequate caloric and nutrient intake should be a high priority for intensive care clinicians. Current guidelines recommend that all ICU patients who tolerate enteral nutrition (EN) should receive EN (approximately $25-30 \mathrm{kcal} / \mathrm{kg}$ per day) if they are not expected to be on a full oral diet within 3 days [8]. However, within the ICU setting EN may not be feasible or cannot be established at rates that provide adequate nutrition for a number of reasons. For example, EN may be frequently interrupted because of diagnostic investigations, surgery, diarrhea, vomiting, mechanical problems (e.g., tube displacement) or patient transfers [9]. EN may be contraindicated in patients with anatomic gastrointestinal disorders, severe diarrhea, and reduced intestinal blood flow [10]. Parenteral nutrition (PN) is therefore recommended under certain circumstances (Table 1) [11].

Despite these recommendations, $\mathrm{PN}$ is often underused. Although PN was once a popular means of administering nutrients, utilization has decreased in recent years because of concerns regarding metabolic complications associated with overfeeding $[12,13]$ and an increased risk of septic complications [8]. It has been suggested that EN is required in order to maintain gut function and is less likely to cause bacterial translocation than $\mathrm{PN}$, although other perspectives exist $[12,14]$. However, available literature suggests that supplementation of EN with PN enhances caloric intake and nutritional status $[1,15]$ and that $\mathrm{PN}$ is as safe as EN in critically ill patients $[16,17]$.

\section{Individualizing nutrition in critically ill patients}

The systemic inflammatory response is associated with metabolic stress in critically ill patients, including an overall increase in metabolic rate, production of reactive species, insulin resistance, and alterations in substrate utilization that result in hyperglycemia (partly because of increased gluconeogenesis), lipolysis, and increased proteolysis relative to protein synthesis, potentially resulting in negative nitrogen balance $[3,4,11,18,19]$. The nutrition provided to patients within the ICU setting should therefore aim to blunt this catabolic state and enhance anabolic activity during recovery while avoiding overfeeding. Administration of dextrose must often be balanced with infusion of insulin to maintain euglycemia and minimize increases in carbon dioxide $\left(\mathrm{CO}_{2}\right)$ production. Amino acids are required to promote nitrogen retention and support protein synthesis [10]. Lipids are generally administered to provide $30 \%$ of total calories, but dosage reduction should be considered when triglyceride concentrations are $>400 \mathrm{mg} / \mathrm{dL}$ [15]. Nutritional requirements vary depending upon the level of metabolic stress; therefore, energy requirements, as well as blood glucose and electrolyte concentrations, should be monitored on a daily basis, and the composition of artificial nutrition adjusted as required [15].
Table 1 Potential indications for parenteral nutrition in intensive care patients [8-10]

\begin{tabular}{ll}
\hline $\begin{array}{l}\text { Parenteral nutrition as a } \\
\text { supplement to enteral nutrition }\end{array}$ & $\begin{array}{l}\text { Parenteral } \\
\text { nutrition alone }\end{array}$ \\
\hline $\begin{array}{l}\text { Enteral nutrition is insufficient to meet } \\
\text { target caloric intake }\end{array}$ & Intolerance to enteral nutrition \\
$\begin{array}{l}\text { Suppression of gastrointestinal activity } \\
\text { (e.g., immediately following injury or } \\
\text { surgery) }\end{array}$ & $\begin{array}{l}\text { Major gut failure (e.g., extensive intestinal } \\
\text { resection) } \\
\text { Conditions preventing adequate nutrient } \\
\text { absorption (e.g., inflammatory bowel disease, } \\
\text { gastric outlet obstruction, intractable vomiting, } \\
\text { severe diarrhea, paralytic ileus) }\end{array}$ \\
&
\end{tabular}




\section{The role of lipid emulsions in parenteral nutrition}

Early PN formulations consisted primarily of high concentrations of glucose and amino acids in order to provide adequate calories [20] and were often associated with a number of complications. Prolonged use of these formulations was associated with essential fatty acid (EFA) deficiency because they did not provide linoleic acid (LA; 18:2 $\omega-6)$ or $\alpha$-linolenic acid (ALA; $18: 3 \omega-3$ ), which are not synthesized by the body and must be obtained from the diet [20-22]. Furthermore, the high dextrose loads provided by early PN solutions were associated with a variety of other complications, such as excessive $\mathrm{CO}_{2}$ production, metabolic stress (increased concentrations of cortisol, epinephrine, and glucagon), fever, and hepatic steatosis [20]. As critical illnesses can be associated with impaired glucose tolerance, overzealous infusion of hypertonic dextrose solutions was often also associated with hyperglycemia, which, if undetected and untreated, can progress to hyperosmolar nonketotic coma [23]. Hyperglycemia can also be associated with an increased incidence of complications in critically ill patients, such as severe infections, multiple organ failure, and increased mortality rates [24].

The incorporation of lipids into PN formulations has addressed many of these issues. Lipids provide a more energy-dense source of calories (approximately $9 \mathrm{kcal} /$ g) than either amino acids $(4 \mathrm{kcal} / \mathrm{g})$ or dextrose monohydrate $(3.4 \mathrm{kcal} / \mathrm{g})$ [22]. Therefore, the fluid volume of PN required to achieve adequate caloric intake can be substantially reduced. The reduced fluid volume and increase in osmolarity of formulations incorporating LEs permit the safe administration of PN via the peripheral and central routes. Formulations with osmolarities $\leq 900 \mathrm{mOsm} / \mathrm{L}$ can be administered peripherally, while highly osmolar formulations can be administered via central veins, which may be of importance in critically ill patients requiring fluid restriction $[10,25]$. Currently available parenteral LEs also contain sufficient LA and ALA to prevent EFA deficiency [21]. Perhaps most importantly, the use of LEs in PN is associated with a reduction in the metabolic complications related to excessive hypertonic glucose infusion because the dextrose load is correspondingly reduced. Results of a study involving critically ill patients with gastric carcinoma, sepsis, colitis or pancreatitis demonstrated that replacement of one-third of the total calories contained in a conventional glucose-amino acid PN formulation with a LE maintained or increased patients' body weight [26]. Plasma glucose concentrations were maintained or reduced, and no cases of hyperglycemia, hyperosmolar nonketotic coma or hypertriglyceridemia were observed [26]. Another study found that ICU patients receiving parenteral fluids unintentionally received $150-600 \mathrm{kcal} /$ day dextrose as a constituent of various fluids and drugs [1]. Therefore, the administration of PN containing LEs may help to prevent hyperglycemia and its complications.

It should be noted that, despite the potential benefits of parenteral lipids, the use of LEs may be limited in some patients. Triglycerides and other components of LEs form artificial chylomicrons, which are hydrolyzed in the body into free fatty acids (FA) and small remnant particles taken up by the liver [22, 27, 28]; the presence of excess phospholipids can also form liposomes, which interfere with lipid metabolism and may result in hypercholesterolemia $[21,22,28]$. When parenteral lipids are given in excess of the liver's ability to process them, hyperlipidemia and hepatic steatosis may occur [21, 22, 28]. Parenteral LEs also commonly contain phytosterols, which may be present in the circulation in quantities large enough to induce cholestasis [28]. Although hepatic impairment is most common among patients on long-term PN [28, 29], critically ill patients are also at increased risk because plasma levels of FA increase with metabolic stress $[27,30]$. Therefore, parenteral LEs should be used with caution in septic patients $[27,28,30]$ and patients with other conditions known to impair hepatic clearance of FA $[28,30]$. In addition to the duration and dose of parenteral LEs and the patient's level of metabolic stress, the oil source of the LE may also affect the relative risk of developing abnormal liver function [21, 22, 28, 31].

\section{Evolution of parenteral lipid emulsions}

Fatty acids

Although LEs contain numerous biologically active compounds, triacylglycerols providing FA are their primary component. Fatty acids are classified according to their structure, in terms of their hydrocarbon chain length (short, medium or long), degree of saturation (number of double bonds), and location of double bonds (counted from the methyl carbon of the hydrocarbon chain) (Table 2) [21, 22, 32]. Fatty acids play key roles in determining the structural integrity and fluidity of cell membranes and can give rise to several important bioactive mediators $[21,22,33]$. They can also regulate the expression of a variety of genes and modulate cell signaling pathways, such as those involved in apoptosis, inflammation, and cell-mediated immune responses. For example, longer-chain FA, such as arachidonic acid (AA; 20:4 $\omega-6$ ), eicosapentaenoic acid (EPA; 20:5 $\omega-3$ ), and docosahexaenoic acid (DHA; 22:6 $\omega-3$ ), are involved in the generation of pro- and anti-inflammatory lipid mediators [22]. 
Table 2 Fatty acid nomenclature and key dietary sources [22, 32]

\begin{tabular}{|c|c|c|c|}
\hline Common name & Chemical name & $\begin{array}{l}\text { Chemical structure } \\
\text { [length of hydrocarbon } \\
\text { chain ( } \mathrm{C} \text { atoms): number } \\
\text { of double bonds and position } \\
\text { of first double bond] }\end{array}$ & Dietary sources \\
\hline Capric & Decanoic & 10:0 & Coconut oil \\
\hline Lauric & Dodecanoic & $12: 0$ & Coconut oil \\
\hline Myristic & Tetradecanoic & 14:0 & Milk \\
\hline Palmitic & Hexadecanoic & 16:0 & $\begin{array}{l}\text { Milk, eggs, animal fats, meat, cocoa butter, } \\
\text { palm oil, fish and fish oils }\end{array}$ \\
\hline Palmitoleic & 9-Hexadecenoic & $16: 1 \omega-7$ & Fish and fish oils \\
\hline Stearic & Octadecanoic & 18:0 & Milk, eggs, animal fats, meat, cocoa butter \\
\hline Oleic & 9-Octadecenoic & $18: 1 \omega-9$ & Milk, eggs, animal fats, meat, cocoa butter, olive oil \\
\hline Linoleic & 9,12 -Octadecadienoic & $18: 2 \omega-6$ & Seeds, seed oils, eggs, animal fats, meat \\
\hline Arachidonic & 5,8,11,14-Eicosatetraenoic & $20: 4 \omega-6$ & Meat, egg lipids, algal oils \\
\hline$\alpha$-Linolenic & $9,12,15$-Octadecatrienoic & $18: 3 \omega-3$ & Seeds, seed oils, green leaves, nuts \\
\hline Eicosapentaenoic & 5,8,11,14,17-Eicosapentaenoic & $20: 5 \omega-3$ & Fish and fish oils \\
\hline Docosapentaenoic & 7,10,13,16,19-Docosapentaenoic & $22: 5 \omega-3$ & Fish and fish oils \\
\hline Docosahexaenoic & $\begin{array}{l}4,7,10,13,16,19- \\
\text { Docosahexaenoic }\end{array}$ & $22: 6 \omega-3$ & Fish and fish oils, algal oils \\
\hline
\end{tabular}

Early parenteral lipid emulsions

The majority of early LEs, which were first included in PN during the 1960 s, were derived from soybean oil, which contains a high concentration of both LA and ALA $[21,22,33]$. These early LEs were demonstrated to efficiently deliver nonglucose energy, thereby reducing the adverse effects associated with intake of high dextrose concentrations [21]. Furthermore, they provided EFA and the fat-soluble vitamins E and $K$ [33]. However, studies published during the 1970s and 1980s found that soybean-oil- and cottonseed-oil-based LEs were associated with a number of adverse immunological effects, such as reduced migration and phagocytosis of granulocytes, which resulted in increased rates of infections, including sepsis [34-37]. The cottonseed-oilbased LE (Lipomul) had such adverse clinical effects (e.g., hemolytic anemia) that it has since been removed from the market.

Minimization of risks associated with parenteral lipids in critical care patients

In an effort to address concerns associated with the soybean-oil-based LEs, alternative sources of FA were investigated [21]. Much of this research focused on minimizing complications to which critically ill patients are particularly susceptible, including oxidative stress, alterations in cell-mediated immunity, inflammation, and thrombosis. Although these are important issues to consider, well-controlled clinical data in critically ill patients are limited, and discrepancies may be observed between studies because of the heterogeneity of the study designs, patient populations, and specific LEs used.

\section{Oxidative stress}

Reactive oxygen species (ROS) can react with and damage cell membranes, lipids, proteins, and DNA through oxidation. Under normal circumstances, ROS may be produced in increased amounts by cells such as neutrophils and macrophages as part of a natural immune response. Levels of ROS are balanced by the neutralizing activity of antioxidant molecules and enzymes, thereby preventing excessive damage to the host $[38,39]$.

Oxidative stress occurs when an imbalance develops because of high ROS levels and/or low antioxidant levels. During critical illness, increased ROS and inflammatory mediator production occurs against a background of compromised antioxidant activity, which is partly due to preexisting nutritional deficiencies and/or suboptimal provision of artificial nutrition. Depletion of the antioxidants selenium and zinc has been observed in trauma and burn patients, while surgery is associated with reductions in vitamins $\mathrm{A}, \mathrm{C}$, and $\mathrm{E}$. This state of imbalance can cause tissue damage and may play an important role in the development of sepsis and multiple organ failure, among other complications (Table 3) [38, 39].

A key consequence of oxidative stress is lipid peroxidation, where ROS react with the double bond of unsaturated lipids, producing unstable lipid peroxides that may cause cell death $[38,39]$. The high number of double bonds present in $\omega-6$ and $\omega-3$ polyunsaturated fatty acids (PUFA) provide targets for lipid peroxidation, and these FA may therefore be associated with an increased risk of oxidative stress [40]. For this reason, the antioxidant $\alpha$-tocopherol (vitamin E) is sometimes added to PUFArich LEs in clinical practice.

Another approach to minimize oxidative stress is the partial replacement of PUFA-rich oils with alternative FA 
Table 3 Diseases and intensive care unit states associated with reactive oxygen species-mediated tissue damage [39]

Septic shock

Acute respiratory distress syndrome

Systemic inflammatory response syndrome

Disseminated intravascular coagulation

Multiple organ dysfunction

Burns

Cardiovascular disease

Diabetes mellitus

Trauma

Reperfusion injury

Cancer

sources, such as oils rich in medium-chain triglycerides (MCT; derived from coconut oil containing mediumchain FA such as capric acid), which are more resistant to oxidative damage [41]. In one study of adults requiring PN, a 1:1 mixture of MCT (derived from coconut oil) and soybean oil (MCT/soybean oil LE) supplemented with $\alpha$ tocopherol demonstrated a reduced propensity to lipid peroxidation when compared with a conventional soybean-oil-based LE (Table 4) [42]. However, a separate study comparing a soybean-oil-based LE with a MCT/ soybean oil LE supplemented with $\alpha$-tocopherol in patients undergoing abdominal surgery found no difference in lipid peroxidation between the two LEs [43].

Metabolism of MCT differs from that of long-chain triglycerides (LCT). Unlike longer-chain FA, MCT require little carnitine for mitochondrial entry, and it has been suggested that their more rapid breakdown may impart an increased production of ketones in critically ill patients [44]. However, this is thought to be a transient phenomenon that is reversible upon discontinuation of MCT infusion and rarely causes clinical problems. However, formulations containing MCT should not be used in patients who develop ketosis or acidosis in the ICU setting [41].

It has been suggested that monounsaturated FA (MUFA; often derived from olive oil, which also provides antioxidants) with only one double bond, such as oleic acid (OA; 18:1 $\omega-9)$, may be less susceptible to lipid peroxidation than $\omega-6$ and $\omega$-3 PUFA with several double bonds. In vitro studies indicated that cells treated with OA or olive oil were associated with less mitochondrial ROS production than cells treated with certain PUFA (e.g., DHA) or a soybean-oil-based LE [45, 46]. In a preclinical rodent study, lipid peroxidation was lower among mice administered OA or olive oil by gavage than among mice administered PUFA (i.e., LA or DHA) or fish oil [47]. In children requiring PN, a LE containing $80 \%$ olive oil led to lower concentrations of certain lipid peroxides than a soybean-oil-based LE (Table 4) [48]. In a separate study involving preterm infants, peroxidation markers were similar between an olive-oil-rich LE supplemented with $\alpha$-tocopherol and a conventional soybean-oil-based LE, whereas vitamin E status was enhanced with olive-oil-rich LE [49].

\section{Cell-mediated immunity}

Fatty acids have been shown to modulate the immune system in a number of ways, influencing cell signaling, gene expression, and apoptosis. In particular, $\omega-6$ PUFA have been associated with reduced migration and phagocytic activity of neutrophils and macrophages, decreased lymphocyte reactivity to microbial antigens, and inhibition of antibody-dependent cellular cytotoxicity $[34,35,50-52]$. The consequences of these immunosuppressive actions have been demonstrated within the ICU setting. When compared with PN containing no lipids administered to trauma patients, PN containing a soybean-oil-based LE was associated with higher rates of infection and significantly longer durations of mechanical ventilation, longer ICU stays, and longer hospital stays (Table 4) [53]. In patients with septic shock, those receiving a soybean-oil-based LE showed increased leukocyte counts and reduced neutrophil cytotoxic activity, while those receiving a fish-oil-based LE experienced opposite effects [54]. However, excessive (hypercaloric) feeding may also have contributed to immunosuppression observed in some older studies.

Among surgical patients receiving PN, a soybean-oilbased LE supplemented with fish oil was associated with a shorter ICU and overall hospital stay when compared with a LE that did not contain fish oil; however, the rates of infection were similar between groups (Table 4) [55]. When a soybean-oil-based LE was supplemented with fish oil, higher doses were associated with a reduction in the length of ICU and overall hospital stay, significantly reduced antibiotic requirement, and significantly increased survival [56].

In comparison with soybean oil, MCT are generally described as immune neutral; however, effects upon certain components of the immune system have been described. In two ex vivo studies, MCT and MCT/soybean oil LEs increased monocyte activation and neutrophil adhesion and degranulation $[57,58]$. In contrast, another ex vivo study reported that MCT and MCT/ soybean oil LEs were both associated with impaired neutrophil killing of Candida albicans [59]. An in vitro study showed that a MCT/soybean oil LE inhibited the proliferation of T-lymphocytes but not lymphokine-activated killer cells [60].

There are few clinical data evaluating the effect of MCT on immune function. In a study involving healthy volunteers, administration of an MCT/soybean oil LE was associated with increased total leukocyte and neutrophil counts and significantly decreased lymphocyte counts [61]. A second study of healthy subjects found that, in contrast to intermittent infusion of soybean-oil-based LE, 


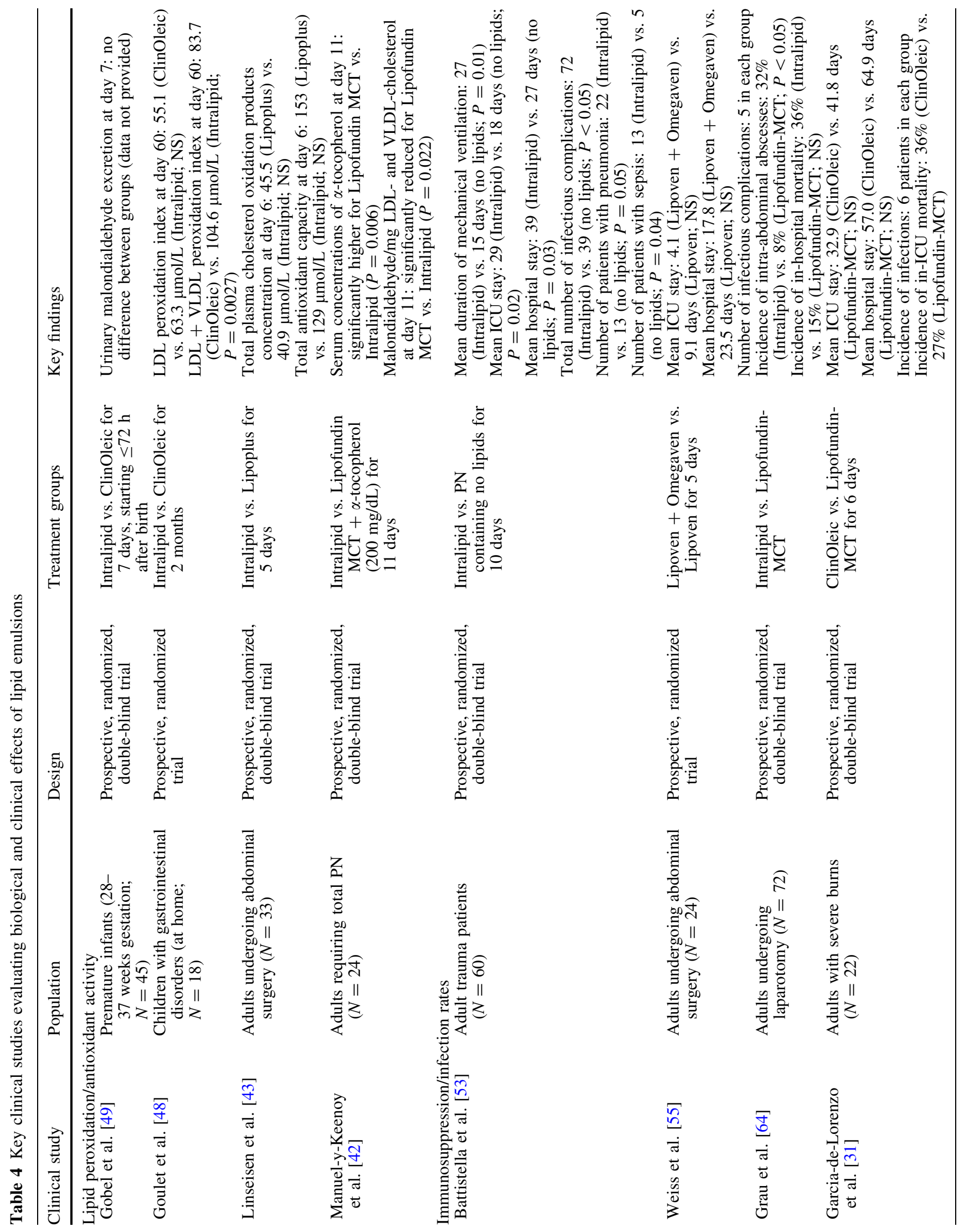




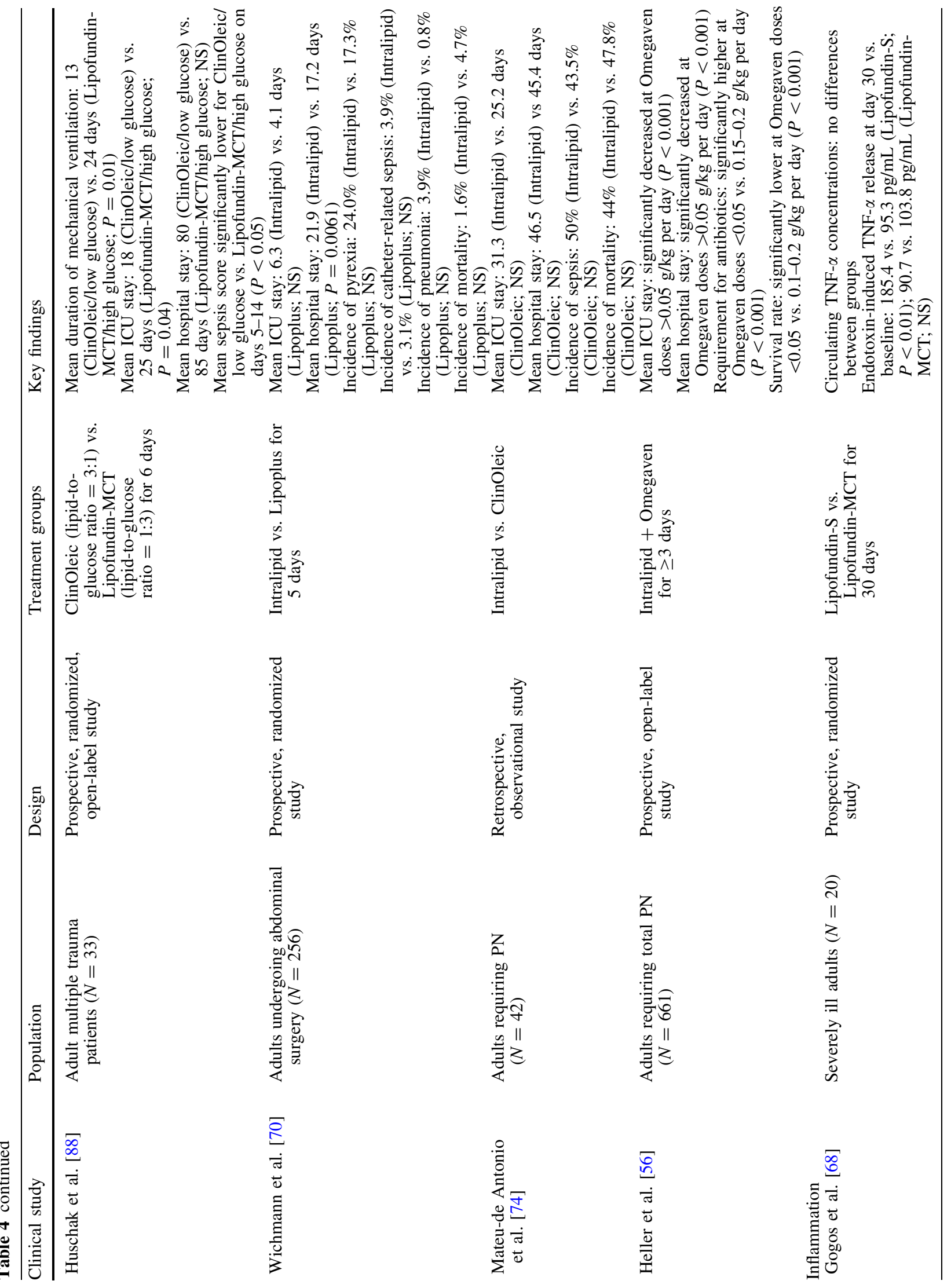




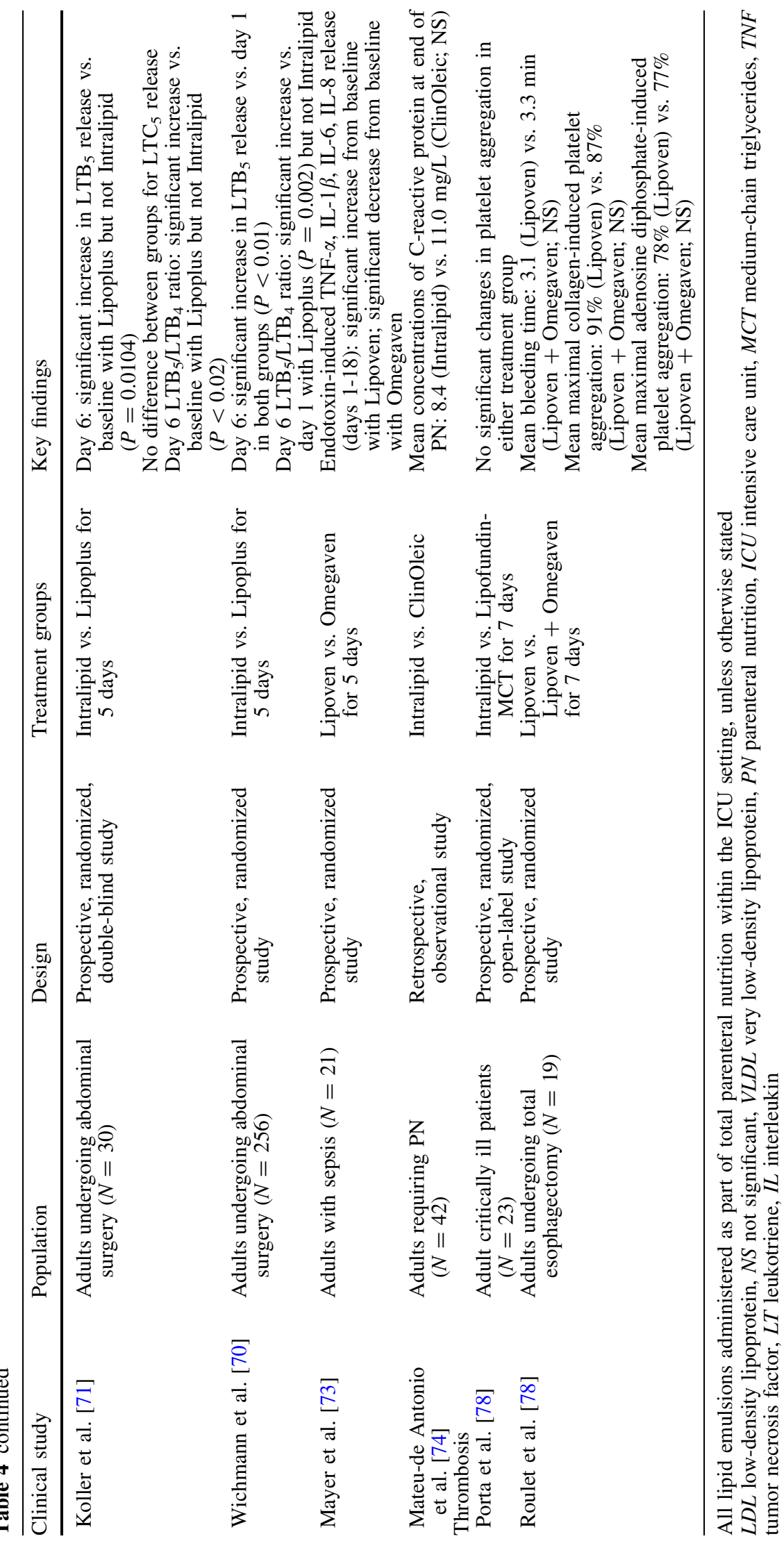


infusion of PN containing MCT/soybean oil LE did not impair the clearance of 99Tc-sulfur colloid by the reticuloendothelial system [62]. In pediatric surgical patients receiving $\mathrm{PN}$, an $\mathrm{MCT} /$ soybean oil $\mathrm{LE}$ was associated with a significantly increased lymphocyte count when compared with a soybean-oil-based LE [63]. Another study compared an MCT/soybean oil LE with a soybeanoil-based LE in severely undernourished patients undergoing laparotomy [64]. In that study, the incidence of intra-abdominal abscesses was significantly lower in the MCT/soybean oil group than the soybean oil group, but there were no significant differences between the groups for other infections (Table 4) [64].

Lipid emulsions containing high concentrations of olive oil may have less impact on the host immune response than soybean-oil-based or MCT/soybean oil LEs, with little effect on lymphocytes, natural killer cells, and neutrophils. In an in vitro study, the percentage of lymphocytes undergoing apoptosis or necrosis was higher following incubation with $200 \mu \mathrm{M}$ LA $(77 \%)$ than with $200 \mu \mathrm{M}$ OA $(23 \%)$; both were higher than the control group (3\%) [65]. Another study showed that lymphocyte activation was dose-dependently inhibited by soybeanoil-based LEs but not an olive-oil-rich LE [66]. In contrast to a MCT/soybean oil LE, an olive-oil-rich LE had little effect on neutrophil activation, phagocytosis, generation of ROS or chemotaxis [67]. The immunosupportive effects of an olive-oil-rich emulsion may be reflected clinically by the low incidence of infectious complications reported in severely burned patients receiving PN in the ICU: in a study evaluating this patient population, the incidences of sepsis and multiple organ failure and the duration of mechanical ventilation, ICU stay, and hospital stay were comparable for patients receiving olive-oil-rich and MCT/soybean oil LEs (Table 4) [31].

\section{Inflammation}

Administration of soybean-oil-based LEs is associated with high blood levels of the $\omega-6$ PUFA LA and its metabolite AA, the further metabolism of which may produce proinflammatory eicosanoids [e.g., prostaglandins, thromboxanes, and leukotrienes (LT)] that can regulate additional inflammatory mediators [e.g., tumor necrosis factor (TNF)- $\alpha$ ] [32]. This hypothesis is supported by a study reporting that malnourished, severely ill patients experienced significantly increased total production of TNF- $\alpha$ when receiving PN with a soybean-oilbased LE but not an MCT/soybean oil LE [68]. Although there has been much focus on the proinflammatory effects of AA-derived eicosanoids, lipoxins derived from AA have potent inflammation-resolving effects [69].

Conversely, the long-chain $\omega$-3 PUFAs EPA and DHA found in fish oils are thought to possess anti-inflammatory properties because they are readily incorporated into cell membranes and thereby impact AA metabolism [18, 32], because the metabolism of EPA is associated with production of less biologically potent eicosanoids than those produced from AA [18, 32], and because EPA and DHA are precursors of resolvins with powerful inflammationresolving properties $[18,69]$. Indeed, when soybean oil was partially replaced with fish oil (3:1 ratio) in surgical patients receiving $\mathrm{PN}$, LT synthesis was shifted from the proinflammatory $\mathrm{LTB}_{4}$ (produced from AA) to the less potent $\mathrm{LTB}_{5}$ (produced from EPA) (Table 4) [70, 71]. This change was associated with significantly reduced concentrations of the inflammatory mediators interleukin (IL)- 6 and TNF- $\alpha$ [72]. In patients with sepsis, concentrations of IL- $1 \beta$, IL- 6 , IL- 8 , and TNF- $\alpha$ released from mononuclear leukocytes were significantly increased following administration of a soybean-oil-based LE compared with a decrease of approximately $30 \%$ following administration of a fish-oil-based LE [73].

Lipid emulsions rich in olive oil have not been well studied with regard to their effect on inflammation; however, a few studies have demonstrated that OA has relatively few effects on the production of inflammatory mediators. In a preclinical study, lipopolysaccharideinduced production of IL- $1 \beta$, IL- 6 , IL- 8 , and TNF- $\alpha$ by neutrophils was not altered by an olive-oil-rich LE, compared with significant reductions in IL- $1 \beta$ with soybean-oil-based and MCT/soybean oil LEs [67]. In another study, infectious complication rates, mortality rates, and length of ICU stay were similar among critically ill patients receiving PN containing soybean-oil-based and olive-oil-rich LEs [74].

\section{Thrombosis}

Thrombosis is a common and serious complication for many critically ill, surgical, and trauma patients, as these states may be associated with changes in the availability of clotting factors and alterations in the fibrinolytic pathway, resulting in intravascular coagulation [75]. However, the effects of LEs on coagulation have not been extensively assessed. In one study, platelet aggregation was inhibited immediately following intravenous infusion of a fish-oil-based LE to healthy volunteers, but had returned to normal at $24 \mathrm{~h}$ [76]. In surgical patients receiving $\mathrm{PN}$, the latency to collagen-induced platelet aggregation and time to maximal platelet aggregation were significantly longer for a soybean-oil-based LE than for a fish-oil-enriched LE; however, adenosine-diphosphate-induced platelet aggregation and bleeding time were unchanged [77]. Another study found no change in platelet aggregation for critically ill patients receiving either soybean-oil-based or MCT/soybean oil LEs [78].

The effects of parenteral olive-oil-rich LEs on thrombosis have not been systematically evaluated. 


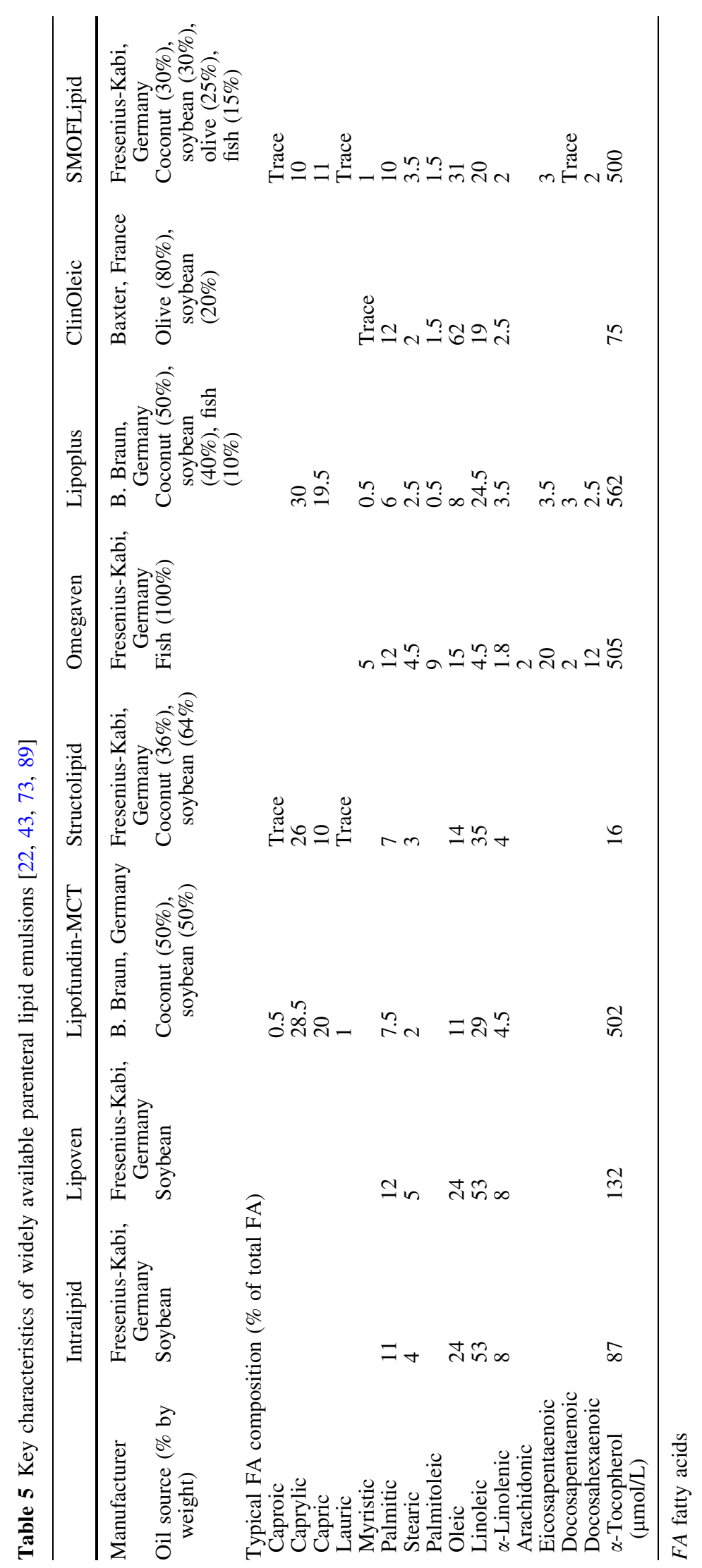


However, in one study of patients undergoing hemodialysis, the need to change hemofilters due to blood coagulation was significantly reduced among patients receiving PN containing an olive-oil-rich LE compared with a soybean-oil-based LE [79].

\section{Choosing a parenteral lipid emulsion for the critically ill patient}

Components of commercially available lipid emulsions

A summary of the key characteristics of available parenteral LEs is presented in Table 5; in some countries (i.e., the USA) only soybean-oil-based LEs are available [8]. The choice of parenteral LE should be based upon several considerations. It has been suggested that the ratio of LA to ALA is important because of competition between these FA for a number of enzymes, thereby potentially influencing the production of eicosanoid and eicosanoid-like inflammatory mediators [80]. However, a number of studies have suggested that the absolute concentrations of certain PUFA are more important than their ratio in determining their biologic effects $[80,81]$. In addition, the FA content of LEs can vary depending upon the specific source of oil (e.g., EPA and DHA within different fish oils) [80].

The stability of LEs, with respect to phase separation and presence of large globules, is also an important issue in clinical settings in which the final concentrations of lipid components and emulsifiers are of key importance. All LEs eventually become unstable when diluted above a certain threshold within the PN formulation. Current regulations in the USA require that globules $>5 \mu \mathrm{m}$ do not exceed $0.05 \%$ (weight/volume) of the emulsion [82]. In general, MCT/soybean oil and olive-oil-rich LEs have demonstrated greater stability when compared with soybean-oil- and safflower-oil-based LEs, although stability may vary between manufacturers $[82,83]$. The stability of MCT/soybean oil LEs may be due to the inclusion of shorter-chain lipids, which exhibit a lower free energy when dispersed in water, resulting in greater miscibility between phases and reduced physicochemical stress on emulsifying agents compared with LEs containing predominantly longer-chain triglycerides [83]. Olive-oil-rich LEs contain sodium oleate, which acts as an additional emulsifying agent and thereby augments stability [83]. In addition, the stability of PN formulations that contain LEs may be affected by interactions between FA and other commonly administered compounds, such as carnitine, heparin, and some vitamins [84-86].

Potential therapeutic roles for lipid emulsions

Lipid emulsions demonstrate different biologic effects depending upon their specific FA content, which may translate into beneficial effects for selected patients (Table 6). The biologic effects associated with LEs are likely to benefit a majority of patients receiving parenteral LEs, including those on long-term total PN, but may have the greatest importance for patients under metabolic stress. Therefore, physicians need to consider several issues when selecting an LE as part of a PN regimen.

All currently available LEs provide sufficient $\omega-6$ and $\omega$-3 EFA, with the exception of $100 \%$ fish oil LE, which should generally only be used as a pharmacological agent or as a supplement to other LEs [21,22]. Although there are conflicting views regarding the comparative utility of different LE formulations in critically ill patients, there is growing consensus that LEs based entirely on soybean oil should be avoided in favor of emulsions in which the LA and ALA content is partially replaced by MCT, olive oil providing MUFA or fish oil providing EPA and DHA. This is particularly true for patients with highly proinflammatory states, such as surgical, trauma, burn, and septic patients $[8,87]$. In addition, the clinical use of LEs should not exacerbate oxidative stress in critically ill patients. Unfortunately, evidence on the differential effects of LEs in critically ill patients remains limited. Furthermore, inconsistencies of findings between studies have suggested that the biologic effects of FA may vary with the medical condition and level of metabolic stress; therefore, further clinical trials exploring the effects of FA in different subpopulations of critically ill patients are highly desirable.
Table 6 Potential therapeutic applications of lipid emulsions

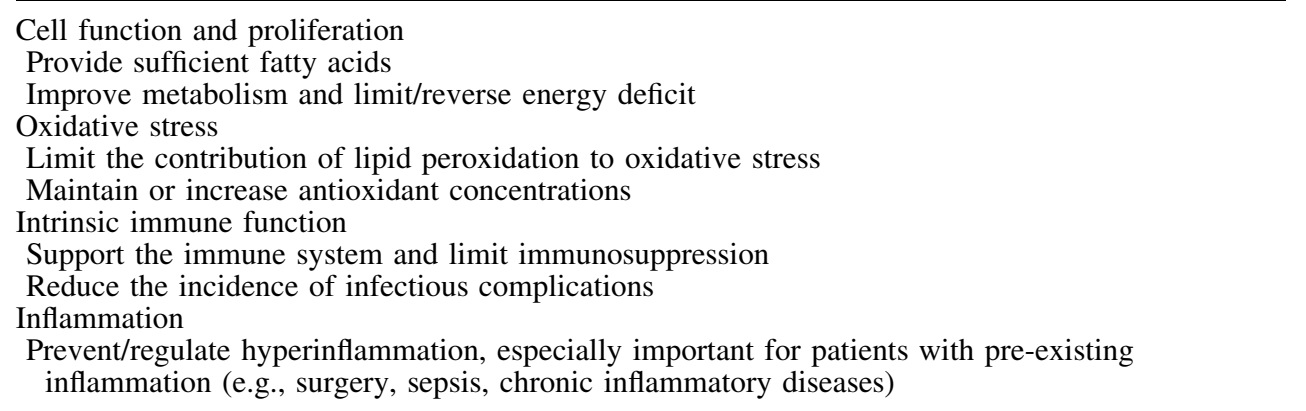

Improve metabolism and limit/reverse energy deficit

Oxidative stress

Maintain or increase antioxidant concentrations

Reduce the incidence of infectious complications

inflammation (e.g., surgery, sepsis, chronic inflammatory diseases) 


\section{Conclusions}

Energy deficit is a major problem among ICU patients and is associated with an increased incidence of complications, length of stay, and mortality. PN, either alone or in combination with $\mathrm{EN}$, can improve caloric delivery to critically ill patients, preventing or correcting energy deficits and improving outcomes. Lipids are an important source of calories in artificial nutrition, and they have demonstrated a wide range of biologic activities that may benefit a variety of patients receiving PN, as well as those receiving EN with or without PN supplementation.

Parenteral lipid emulsions derived from soybean oil are the most extensively evaluated formulations in preclinical and clinical studies and have demonstrated efficacy and safety in delivering vital nutrition to critically ill patients. Newer LEs that utilize partial substitution of soybean oil with MCT, olive oil or fish oil either alone or in combination have demonstrated potential benefits in terms of reduced impacts on oxidative stress and differential effects on cell-mediated immunity and inflammation. However, few published studies have evaluated the biologic effects of newer parenteral LEs, and data assessing the clinical benefits of these newer formulations are limited and sometimes inconsistent because of the heterogeneity of the study designs and patient populations. Ongoing research to further characterize and compare the biologic properties of lipids given parenterally, as well as enterally, will be an important resource for physicians, especially those managing critically ill patients, who are often under metabolic stress. These studies must be adequately designed and well controlled. Until then, the prescription of LEs should be based upon the limited clinical data available, the range of available LEs, cost implications, and an understanding of the potential biologic effects of their components, bearing in mind the situation and therapeutic goals of the individual patient.

Acknowledgments Editorial assistance was provided by Kimberly Brooks, PhD, of MedErgy (Yardley, PA).

Conflict of interest statement The writing of this manuscript was financially supported by a grant from Baxter Healthcare, Deerfield, IL, USA to MedErgy, Yardley, PA. All authors were financially supported by Baxter Healthcare to attend a workshop on lipid emulsions held in May 2008 in Rome, Italy. P.C.C. has received speaking honoraria from B. Braun, Baxter Healthcare, Fresenius-Kabi, and Abbott Nutrition and has received research funding from B. Braun. B.V.K. has received speaking honoraria and research funding from B. Braun, Baxter Healthcare, and Fresenius-Kabi. P.S. has received speaking honoraria from Abbott Nutrition, Baxter Healthcare, and Fresenius-Kabi and research funding from B. Braun and Fresenius-Kabi. G.J.A.W. has received speaking honoraria from Baxter Healthcare and Fresenius-Kabi. G.L.J. has received speaking honoraria and/or consulting fees from Baxter Healthcare, Nestle Nutrition, and Abbott Nutrition.

Open Access This article is distributed under the terms of the Creative Commons Attribution Noncommercial License which permits any noncommercial use, distribution, and reproduction in any medium, provided the original author(s) and source are credited.

\section{References}

1. Villet S, Chiolero RL, Bollmann MD, Revelly JP, Cayeux RNM, Delarue J, Berger MM (2005) Negative impact of hypocaloric feeding and energy balance on clinical outcome in ICU patients. Clin Nutr 24:502-509

2. Dvir D, Cohen J, Singer P (2006) Computerized energy balance and complications in critically ill patients: an observational study. Clin Nutr 25:37-44

3. Hill GL (1998) Implications of critical illness, injury, and sepsis on lean body mass and nutritional needs. Nutrition 14:557-558

4. Hadley JS, Hinds CJ (2002) Anabolic strategies in critical illness. Curr Opin Pharmacol 2:700-707

5. Petros S, Engelmann L (2006) Enteral nutrition delivery and energy expenditure in medical intensive care patients. Clin Nutr 25:51-59
6. Artinian V, Krayem H, DiGiovine B (2006) Effects of early enteral feeding on the outcome of critically ill mechanically ventilated medical patients. Chest 129:960-967

7. Desachy A, Clavel M, Vuagnat A, Normand S, Gissot V, Francois B (2008) Initial efficacy and tolerability of early enteral nutrition with immediate or gradual introduction in intubated patients. Intensive Care Med 34:10541059

8. McClave SA, Martindale RG, Vanek VW, McCarthy M, Roberts P, Taylor B, Ochoa JB, Napolitano L, Cresci G (2009) Guidelines for the provision and assessment of nutrition support therapy in the adult critically ill patient: Society of Critical Care Medicine (SCCM) and American Society for Parenteral and Enteral Nutrition (A.S.P.E.N.). JPEN J Parenter Enteral Nutr 33:277-316

9. Woodcock NP, Zeigler D, Palmer MD, Buckley P, Mitchell CJ, Macfie J (2001) Enteral versus parenteral nutrition: a pragmatic study. Nutrition 17:1-12
10. Chan S, McCowen KC, Blackburn GL (1999) Nutrition management in the ICU. Chest 115:145S-148S

11. Singer $P$, Berger MM, van den BG, Biolo G, Calder P, Forbes A, Griffiths R, Kreyman G, Leverve X, Pichard C (2009) ESPEN guidelines on parenteral nutrition: intensive care. Clin Nutr 28:387-400

12. Jeejeebhoy KN (2001) Total parenteral nutrition: potion or poison? Am J Clin Nutr 74:160-163

13. Klein CJ, Stanek GS, Wiles CE III (1998) Overfeeding macronutrients to critically ill adults: metabolic complications. J Am Diet Assoc 98:795-806

14. Reynolds JV, Kanwar S, Welsh FK, Windsor AC, Murchan P, Barclay GR, Guillou PJ (1997) 1997 Harry M. Vars Research Award. Does the route of feeding modify gut barrier function and clinical outcome in patients after major upper gastrointestinal surgery? JPEN J Parenter Enteral Nutr 21:196-201 
15. Huang YC, Yen CE, Cheng CH, Jih KS, Kan MN (2000) Nutritional status of mechanically ventilated critically ill patients: comparison of different types of nutritional support. Clin Nutr 19:101-107

16. Heyland DK, MacDonald S, Keefe L, Drover JW (1998) Total parenteral nutrition in the critically ill patient: a meta-analysis. JAMA 280:2013-2019

17. Simpson F, Doig GS (2005) Parenteral vs. enteral nutrition in the critically ill patient: a meta-analysis of trials using the intention to treat principle. Intensive Care Med 31:12-23

18. Singer P, Shapiro H, Theilla M, Anbar R, Singer J, Cohen J (2008) Antiinflammatory properties of omega-3 fatty acids in critical illness: novel mechanisms and an integrative perspective. Intensive Care Med 34:1580-1592

19. Marik PE, Zaloga GP (2008) Immunonutrition in critically ill patients: a systematic review and analysis of the literature. Intensive Care Med 34:1980-1990

20. Vinnars E, Hammarqvist F (2004) 25th Arvid Wretlind's Lecture-Silver anniversary, 25 years with ESPEN, the history of nutrition. Clin Nutr 23:955-962

21. Waitzberg DL, Torrinhas RS, Jacintho TM (2006) New parenteral lipid emulsions for clinical use. JPEN J Parenter Enteral Nutr 30:351-367

22. Wanten GJA, Calder PC (2007) Immune modulation by parenteral lipid emulsions. Am J Clin Nutr 85:1171-1184

23. Dudrick SJ, Macfadyen BV Jr, Van Buren CT, Ruberg RL, Maynard AT (1972) Parenteral hyperalimentation. Metabolic problems and solutions. Ann Surg 176:259-264

24. Van den Berghe G, Wouters P, Weekers F, Verwaest C, Bruyninckx F, Schetz M, Vlasselaers D, Ferdinande P, Lauwers P, Bouillon R (2001) Intensive insulin therapy in the critically ill patients. N Engl J Med 345:1359-1367

25. Pittiruti M, Hamilton H, Biffi R, Macfie J, Pertkiewicz M (2009) ESPEN guidelines on parenteral nutrition: central venous catheters (access, care, diagnosis and therapy of complications). Clin Nutr 28:365-377

26. Meguid MM, Schimmel E, Johnson WC, Meguid V, Lowell BC, Bourinski J, Nabseth DC (1982) Reduced metabolic complications in total parenteral nutrition: pilot study using fat to replace one-third of glucose calories. JPEN J Parenter Enteral Nutr 6:304-307

27. Atkinson M, Worthley LI (2003) Nutrition in the critically ill patient: part I. Essential physiology and pathophysiology. Crit Care Resusc 5:109-120
28. Kumpf VJ (2006) Parenteral nutritionassociated liver disease in adult and pediatric patients. Nutr Clin Pract 21:279-290

29. Cavicchi M, Beau P, Crenn P, Degott C, Messing B (2000) Prevalence of liver disease and contributing factors in patients receiving home parenteral nutrition for permanent intestinal failure. Ann Intern Med 132:525-532

30. Miles JM (1993) Lipid fuel metabolism in health and disease. Curr Opin Gen Surg 78-84

31. García-de-Lorenzo A, Denia R, Atlan P, Martinez-Ratero S, Le BA, Evard D, Bereziat G (2005) Parenteral nutrition providing a restricted amount of linoleic acid in severely burned patients: a randomised double-blind study of an olive oil-based lipid emulsion v. medium/long-chain triacylglycerols. $\mathrm{Br}$ J Nutr 94:221-230

32. Calder PC (2003) Long-chain n-3 fatty acids and inflammation: potential application in surgical and trauma patients. Braz J Med Biol Res 36:433446

33. Carpentier YA, Dupont IE (2000) Advances in intravenous lipid emulsions. World J Surg 24:1493-1497

34. Jarstrand C, Berghem L, Lahnborg G (1978) Human granulocyte and reticuloendothelial system function during intralipid infusion. JPEN J Parenter Enteral Nutr 2:663-670

35. Nordenstrom J, Jarstrand C, Wiernik A (1979) Decreased chemotactic and random migration of leukocytes during intralipid infusion. Am J Clin Nutr 32:2416-2422

36. Snydman DR, Murray SA, Kornfeld SJ, Majka JA, Ellis CA (1982) Total parenteral nutrition-related infections. Prospective epidemiologic study using semiquantitative methods. Am J Med 73:695-699

37. Mueller JF, Viteri F (1965) Hematologic studies in patients receiving multiple infusions of Lipomul I. V. Am J Clin Nutr 16:151-155

38. Mishra V (2007) Oxidative stress and role of antioxidant supplementation in critical illness. Clin Lab 53:199-209

39. Goodyear-Bruch C, Pierce JD (2002) Oxidative stress in critically ill patients. Am J Crit Care 11:543-551

40. Hardy G, Allwood MC (1997) Oxidation of intravenous lipid emulsions. Nutrition 13:230

41. Ulrich H, Pastores SM, Katz DP, Kvetan V (1996) Parenteral use of medium-chain triglycerides: a reappraisal. Nutrition 12:231-238
42. Manuel-y-Keenoy B, Nonneman L, De Bosscher H, Vertommen J, Schrans S, Klutsch K, De Leeuw I (2002) Effects of intravenous supplementation with alpha-tocopherol in patients receiving total parenteral nutrition containing medium- and long-chain triglycerides. Eur J Clin Nutr 56:121-128

43. Linseisen J, Hoffmann J, Lienhard S, Jauch KW, Wolfram G (2000) Antioxidant status of surgical patients receiving TPN with an omega-3-fatty acid-containing lipid emulsion supplemented with alpha-tocopherol. Clin Nutr 19:177-184

44. Ball MJ (1993) Parenteral nutrition in the critically ill: use of a medium chain triglyceride emulsion. Intensive Care Med 19:89-95

45. Tirosh O, Ilan E, Anavi S, Ramadori G, Madar Z (2009) Nutritional lipidinduced oxidative stress leads to mitochondrial dysfunction followed by necrotic death in $\mathrm{FaO}$ hepatocytes. Nutrition 25:200-208

46. Watkins SM, Carter LC, German JB (1998) Docosahexaenoic acid accumulates in cardiolipin and enhances HT-29 cell oxidant production. J Lipid Res 39:1583-1588

47. Fuhrman B, Volkova N, Aviram M (2006) Postprandial serum triacylglycerols and oxidative stress in mice after consumption of fish oil, soy oil or olive oil: possible role for paraoxonase-1 triacylglycerol lipaselike activity. Nutrition 22:922-930

48. Goulet O, de Potter S, Antébi H, Driss F, Colomb V, Bereziat G, Alcindor LG, Corriol O, Le BA, Dutot G, Forget D, Perennec V, Ricour C (1999) Longterm efficacy and safety of a new olive oil-based intravenous fat emulsion in pediatric patients: a double-blind randomized study. Am J Clin Nutr 70:338-345

49. Göbel Y, Koletzko B, Bohles HJ, Engelsberger I, Forget D, Le BA, Peters J, Zimmermann A (2003) Parenteral fat emulsions based on olive and soybean oils: a randomized clinical trial in preterm infants. J Pediatr Gastroenterol Nutr 37:161-167

50. Francis DM, Shenton BK (1987) Fat emulsion adversely affects lymphocyte reactivity. Aust N Z J Surg 57:323-329

51. Loo LS, Tang JP, Kohl S (1982) Inhibition of cellular cytotoxicity of leukocytes for herpes simplex virusinfected cells in vitro and in vivo by intralipid. J Infect Dis 146:64-70

52. Sedman PC, Somers SS, Ramsden CW, Brennan TG, Guillou PJ (1991) Effects of different lipid emulsions on lymphocyte function during total parenteral nutrition. Br J Surg 78:13961399 
53. Battistella FD, Widergren JT, Anderson JT, Siepler JK, Weber JC, MacColl K (1997) A prospective, randomized trial of intravenous fat emulsion administration in trauma victims requiring total parenteral nutrition. J Trauma 43:52-58

54. Mayer K, Fegbeutel C, Hattar K, Sibelius U, Kramer HJ, Heuer K-U, Temmesfeld-Wollbruck B, Gokorsch S, Grimminger F, Seeger W (2003) $\omega-3$ vs. $\omega-6$ lipid emulsions exert differential influence on neutrophils in septic shock patients: impact on plasma fatty acids and lipid mediator generation. Intensive Care Med 29:1472-1481

55. Weiss G, Meyer F, Matthies B, Pross M, Koenig W, Lippert H (2002) Immunomodulation by perioperative administration of $\mathrm{n}-3$ fatty acids. Br J Nutr 87(Suppl 1):S89-S94

56. Heller AR, Rossler S, Litz RJ, Stehr SN, Heller SC, Koch R, Koch T (2006) Omega-3 fatty acids improve the diagnosis-related clinical outcome. Crit Care Med 34:972-979

57. Wanten GJ, Geijtenbeek TB, Raymakers RA, van KY, Roos D, Jansen JB, Naber AH (2000) Mediumchain, triglyceride-containing lipid emulsions increase human neutrophil beta2 integrin expression, adhesion, and degranulation. JPEN J Parenter Enteral Nutr 24:228-233

58. Versleijen M, Roelofs H, Preijers F, Roos D, Wanten G (2005) Parenteral lipids modulate leukocyte phenotypes in whole blood, depending on their fatty acid composition. Clin Nutr 24:822-829

59. Wanten GJ, Curfs JH, Meis JF, Naber AH (2001) Phagocytosis and killing of Candida albicans by human neutrophils after exposure to structurally different lipid emulsions. JPEN J Parenter Enteral Nutr 25:9-13

60. Sedman PC, Ramsden CW, Brennan TG, Guillou PJ (1990) Pharmacological concentrations of lipid emulsions inhibit interleukin-2-dependent lymphocyte responses in vitro. JPEN J Parenter Enteral Nutr 14:12-17

61. Versleijen MW, Oyen WJ, Roelofs HM, van Emst-De Vries SE, Willems PH, Jansen JB, Wanten GJ (2008) Immune function and leukocyte sequestration under the influence of parenteral lipid emulsions in healthy humans: a placebo-controlled crossover study. Am J Clin Nutr 87:539-547

62. Jensen GL, Mascioli EA, Seidner DL, Istfan NW, Domnitch AM, Selleck K, Babayan VK, Blackburn GL, Bistrian BR (1990) Parenteral infusion of longand medium-chain triglycerides and reticuloendothelial system function in man. JPEN J Parenter Enteral Nutr $14: 467-471$
63. Lai H, Chen W (2000) Effects of medium-chain and long-chain triacylglycerols in pediatric surgical patients. Nutrition 16:401-406

64. Grau T, Ruiz de Adana JC, Zubillaga S, Fuerte S, Giron C (2003) Randomized study of two different fat emulsions in total parenteral nutrition of malnourished surgical patients; effect of infectious morbidity and mortality. Nutr Hosp 18:159-166

65. Cury-Boaventura MF, Gorjao R, de Lima TM, Newsholme P, Curi R (2006) Comparative toxicity of oleic and linoleic acid on human lymphocytes. Life Sci 78:1448-1456

66. Granato D, Blum S, Rössle C, Le Boucher J, Malnoë A, Dutot G (2000) Effects of parenteral lipid emulsions with different fatty acid composition on immune cell functions in vitro. JPEN J Parenter Enteral Nutr 24:113-118

67. Buenestado A, Cortijo J, Sanz MJ, Naim-Abu-Nabah Y, Martinez-Losa M, Mata M, Issekutz AC, Marti-Bonmati E, Morcillo EJ (2006) Olive oil-based lipid emulsion's neutral effects on neutrophil functions and leukocyteendothelial cell interactions. JPEN J Parenter Enteral Nutr 30:286-296

68. Gogos CA, Zoumbos N, Makri M, Kalfarentzos F (1994) Medium- and long-chain triglycerides have different effects on the synthesis of tumor necrosis factor by human mononuclear cells in patients under total parenteral nutrition. J Am Coll Nutr 13:40-44

69. Serhan CN (2008) Systems approach with inflammatory exudates uncovers novel anti-inflammatory and proresolving mediators. Prostaglandins Leukot Essent Fatty Acids 79:157-163

70. Wichmann MW, Thul P, Czarnetzki HD, Morlion BJ, Kemen M, Jauch KW (2007) Evaluation of clinical safety and beneficial effects of a fish oil containing lipid emulsion (Lipoplus, MLF541): data from a prospective, randomized, multicenter trial. Crit Care Med 35:700-706

71. Koller M, Senkal M, Kemen M, Konig W, Zumtobel V, Muhr G (2003) Impact of omega-3 fatty acid enriched TPN on leukotriene synthesis by leukocytes after major surgery. Clin Nutr 22:59-64

72. Wachtler P, Konig W, Senkal M, Kemen M, Koller M (1997) Influence of a total parenteral nutrition enriched with omega- 3 fatty acids on leukotriene synthesis of peripheral leukocytes and systemic cytokine levels in patients with major surgery. J Trauma 42:191-198

73. Mayer K, Gokorsch S, Fegbeutel C, Hattar K, Rosseau S, Walmrath D, Seeger W, Grimminger F (2003) Parenteral nutrition with fish oil modulates cytokine response in patients with sepsis. Am J Respir Crit Care Med 167:1321-1328
74. Mateu-de Antonio J, Grau S, Luque S, Marin-Casino M, Albert I, Ribes E (2008) Comparative effects of olive oilbased and soyabean oil-based emulsions on infection rate and leucocyte count in critically ill patients receiving parenteral nutrition. Br J Nutr 99:846-854

75. Crowther MA, Cook DJ (2008) Thromboprophylaxis in medicalsurgical critically ill patients. Curr Opin Crit Care 14:520-523

76. Elmadfa I, Stroh S, Brandt K, Schlotzer E (1993) Influence of a single parenteral application of a $10 \%$ fish oil emulsion on plasma fatty acid pattern and the function of thrombocytes in young adult men. Ann Nutr Metab 37:8-13

77. Roulet M, Frascarolo P, Pilet M, Chapuis G (1997) Effects of intravenously infused fish oil on platelet fatty acid phospholipid composition and on platelet function in postoperative trauma. JPEN J Parenter Enteral Nutr 21:296-301

78. Porta I, Planas M, Pico M, Soriano B, Martin M, Padro JB, Schwartz S (1993) The effect of 2 lipid emulsions on platelet function. Nutr Hosp 8:339-347

79. Verdier P, Mellot-Verdier I, Chausset R (2002) Lipid emulsions and hemofilter duration in continuous hemodiafiltration. Nutr Clin Metabol 16:85-90

80. Stanley JC, Elsom RL, Calder PC, Griffin BA, Harris WS, Jebb SA, Lovegrove JA, Moore CS, Riemersma RA, Sanders TA (2007) UK Food Standards Agency Workshop Report: the effects of the dietary n-6:n-3 fatty acid ratio on cardiovascular health. Br J Nutr 98:1305-1310

81. Schaeffer L, Gohlke H, Muller M, Heid IM, Palmer LJ, Kompauer I, Demmelmair H, Illig T, Koletzko B, Heinrich J (2006) Common genetic variants of the FADS1 FADS2 gene cluster and their reconstructed haplotypes are associated with the fatty acid composition in phospholipids. Hum Mol Genet 15:1745-1756

82. Driscoll DF (2007) Globule-size distribution in injectable $20 \%$ lipid emulsions: Compliance with USP requirements. Am J Health Syst Pharm 64:2032-2036

83. Driscoll DF, Giampietro K, Wichelhaus DP, Peterss H, Nehne J, Niemann W, Bistrian BR (2001) Physicochemical stability assessments of lipid emulsions of varying oil composition. Clin Nutr 20:151-157

84. Berger MM, Shenkin A (2006) Vitamins and trace elements: practical aspects of supplementation. Nutrition 22:952-955 
85. Kitchen P, Forbes A (2000) Intravenous nutrition: focus on delivery (3-in-1 bags or not?). Curr Opin Gastroenterol 16:184-187

86. Van Aerde T (2004) In preterm infants, does the supplementation of carnitine to parenteral nutrition improve the following clinical outcomes: growth, lipid metabolism and apneic spells? Part A: evidence-based answer and summary. Paediatr Child Health 9:571572
87. Calder PC (2007) Immunonutrition in surgical and critically ill patients. Br J Nutr 98(Suppl 1):S133-S139

88. Huschak G, Zur NK, Hoell T, Riemann D, Mast H, Stuttmann R (2005) Olive oil based nutrition in multiple trauma patients: a pilot study. Intensive Care Med 31:1202-1208
89. Grimm H, Mertes N, Goeters C, Schlotzer E, Mayer K, Grimminger F, Furst P (2006) Improved fatty acid and leukotriene pattern with a novel lipid emulsion in surgical patients. Eur J Nutr 45:55-60 